Original Research Paper

\title{
Multimode Controller Design for DSTATCOM integrated with Battery Energy Storage for Smart Grid Applications
}

\author{
Sai Pranith and T.S. Bhatti \\ Centre for Energy Studies, IIT Delhi, New Delhi, India
}

\author{
Article history \\ Received: 27-08-2017 \\ Revised: $18-10-2017$ \\ Accepted: 26-10-2017 \\ Corresponding Author: \\ Sai Pranith \\ Centre for Energy Studies, IIT \\ Delhi, New Delhi, India \\ Email: saipranith.iitd@gmail.com
}

\begin{abstract}
A Distribution Static Compensator (DSTATCOM) can provide reactive power support, power factor correction and voltage regulation to a distribution system feeder. In this paper, a multimode multifunctional control algorithm is proposed for the controller of the Voltage Source Converter (VSC) to provide DSTATCOM and load leveling functionalities for smart grid applications through a Battery Energy Storage System (BESS) connected to the grid through the VSC. The designed controller enables the VSC to function in both grid-connected and standalone modes of operation. In grid-connected mode, the VSC provides load leveling, dynamic reactive power exchange and unity power factor functionalities based on consumer's choice. When a fault occurs on the grid, the controller opens the circuit breaker and isolates the load from the grid and then switches to the voltage controller for the standalone mode of operation. The novelty of the proposed controller is, the inverter structure which provides load leveling and DSTATCOM functionalities during grid-connected mode will also serve the load during a grid failure, thereby providing uninterrupted power supply to the load. The simulation results show the ability of the proposed multimode controller to successfully operate the multifunctional DSTATCOM-BESS system in various modes.
\end{abstract}

Keywords: Smart Grid, Load Leveling, Inverter, DSTATCOM, Battery Energy Storage

\section{Introduction}

The main purpose of the "Smart Grid" can be defined as 'to enhance the power system infrastructure using communication technology, power electronic technologies and storage technologies and to operate in such a manner that production and consumption are balanced at all levels, i.e., from the highest voltage level to the domestic customer level' (Bollen et al., 2010; Isa et al., 2016). In the Department of Energy report, the six main advantages of Smart Grid have been explained with regards to reliability, economics, efficiency, ecofriendly, security and safety (Hamilton et al., 2010). In this scenario, there are possible issues that arise both on the generation side and on the consumer side.

The fluctuating nature of some renewable energy sources, such as photovoltaics and wind, makes it difficult to predict the power generation that can be obtained through these prime sources. Further, the peaks of power demand may not necessarily coincide with the peaks of generation. Hence, battery systems are required to provide power supply the local loads without interruption (Alanne and Saari, 2006; Gao, 2015). Further batteries can be utilized to provide load leveling functionality (Zurfi and Zhang, 2016). Load leveling can be defined as the process where power is conserved in the battery during light load conditions so that it can be utilized during the periods of high demand. This allows for the postponement of increasing the generation capacity and grid upgrades (The ABB Group Brochure., 2012).

At the distribution systems level, the major power consumption is in the form of the loads that consume reactive power such as fans, pumps etc. These loads draw lagging power factor currents and give rise to reactive power burden on the utilities (Reddy and Reddy, 2012; Singh et al., 2015). The reactive power demand causes losses on the distribution system and also reduces the active power flow capability of the feeder due to the limited current carrying capacity of the feeder conductor. To address these issues, various reactive power compensating devices are proposed both at the transmission and at the distribution levels ( $\mathrm{Pal}$ et al., 
2008). Among these devices, the DSTATCOM can be used for the compensation of reactive power and power factor correction at the distribution level (Chen and Hsu, 2008). The performance of DSTATCOM depends on the control technique used for extraction of the reference current components. For this purpose, many control schemes have been reported in the literature and some of these are instantaneous reactive power theory, instantaneous symmetrical components, synchronous reference frame theory etc (Akagi et al., 2007; Singh et al., 2015)

The review works on DSTATCOM (Pal et al., 2008; Barghi Latran et al., 2015) show that most of the work was centered around proposing various control strategies for the DSTATCOM and to provide various functionalities. Some researchers have proposed the integration of DSTATCOM with battery storage system for power quality improvement (Molina and Mercado, 2006; Mahela and Shaik, 2016), for flicker mitigation (Virulkar and Aware, 2009). But in all these studies, the system works only in grid-connected mode. Though the battery is available, the systems cannot supply to load during grid power interruptions.

To address this issue, we have proposed a multimode controller with integrated fault detection mechanism and a standalone mode controller for the DSTATCOM-BESS system, so that when there is a grid failure, the load can be safely isolated from grid and supplied by the battery using the same inverter structure which was providing load leveling and DSTATCOM functions in gridconnected mode. Hence, our main focus is to design a multimode control structure for the VSC operating in the following modes of operation.

Grid-connected mode: In this mode, power control with indirect current control is employed to independently control real and reactive powers. Using grid real power, load leveling function is provided for real power such that a constant real power is consumed from grid irrespective of varying loads. The reactive power is controlled to provide DSTATCOM functionalities and the consumer can choose to either operate in reactive power exchange or in unity power factor mode, completely taking care of all the reactive power requirements at the load side. These modes can be obtained by changing the grid reactive power reference.

Fault detection and isolation: The controller employs grid voltage based fault detection feature to detect the fault and switch the control to voltage controller (Banu et al., 2014; Vetrivel et al., 2013)

Standalone mode: In this mode, the voltage controller provides the voltage needed for the load from the BESS. This enables uninterrupted power supply to the load during interruptions.

Further, when the Capacitor is connected in shunt, it won't allow DC component to flow through it. It will bypass the $\mathrm{AC}$ component and will filter out the $\mathrm{AC}$ component present in the output of the inverter and thereby reduces the ripple. Even passive filters can be designed to reduce harmonics (Shuja Khan et al., 2011). By implementing above measures, the inverter usage is improved and continuity of supply to the load is maintained during power interruptions. The following sections of this paper explain the configuration and controls in various modes of operation to meet the desired objectives. The simulation results are provided to show the performance of the multimode control structure for various functionalities in both grid-connected and standalone modes of operations along with fault detection and isolation.

\section{System Configuration and Control Strategies for the Integrated DSTATCOM-BESS System}

The overall circuit diagram of the DSTATCOMBESS system shown in Fig. 1. The proposed multimode multifunctional controller comprises of two different controls, one for grid-connected mode and another for UPS mode and also has a fault detection mechanism to chose the appropriate mode of operation. This system can perform 5 different functions:

1. Load leveling

2. Fixed reactive power exchange with grid

3. Unity Power Factor (UPF) mode where grid supplies only the active power

4. Fault detection and mode transfer, when there is a fault on the grid side

5. Uninterrupted power supply (UPS) mode in the absence of the grid

The first three functions (1, 2 and 3$)$ are designed for grid connected mode of operation. Functions (4 and 5) are designed for fault detection and operation in UPS mode.

\section{Grid-Connected Operation}

This section focuses on the control schematics used in decoupling active and reactive power as well as regulation of the active power and the reactive power exchange using the Synchronous Reference Frame theory. In this work, the 'indirect current control' is utilized where the grid currents are utilized instead of load currents for power calculations (Singh et al., 2015). Thus, the Pgrid and $\mathrm{Q}_{\text {grid }}$ can be directly sent to the controller to control the output of the VSC. The reference currents calculation unit, which receives the required real power $\left(\mathrm{P}^{*}\right)$ and the required reactive power $\left(\mathrm{Q}^{*}\right)$ from the external control system. The two loop control structure is shown in Fig. 2. The outer loops control grid active power $\left(\mathrm{P}_{\text {grid }}\right)$ and grid reactive power $\left(\mathrm{Q}_{\text {grid }}\right)$ exchange. 


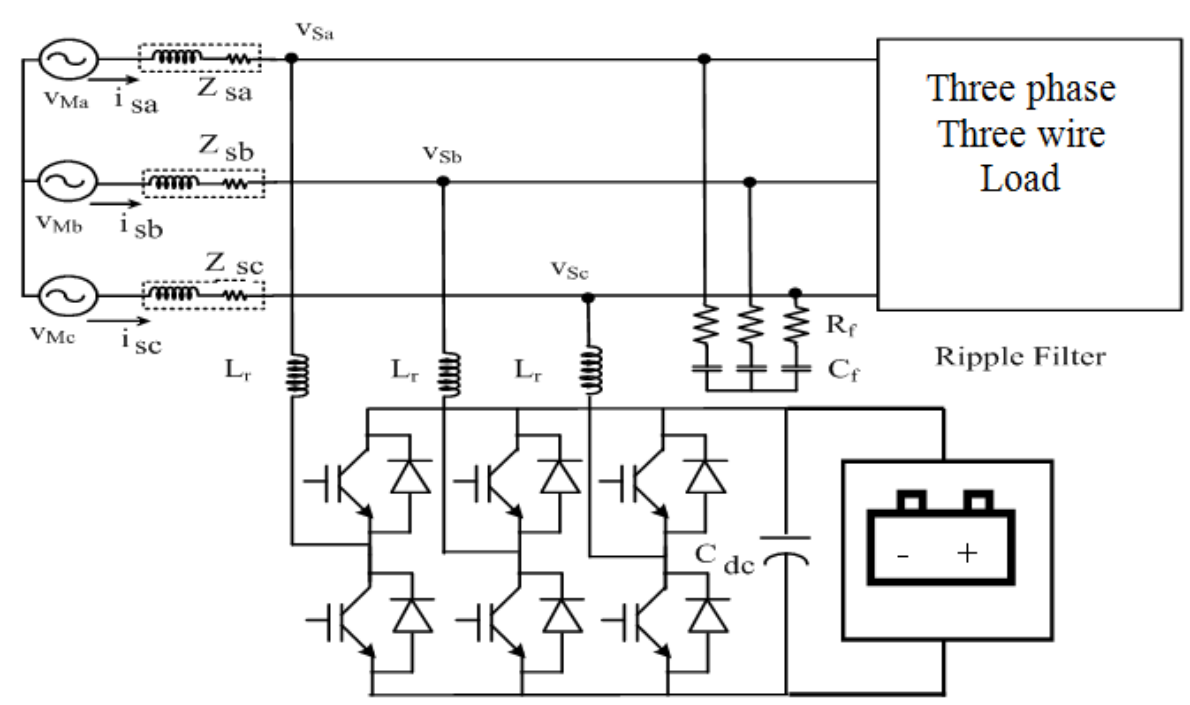

Fig. 1. Overall representation of the DSTATCOM - BESS system

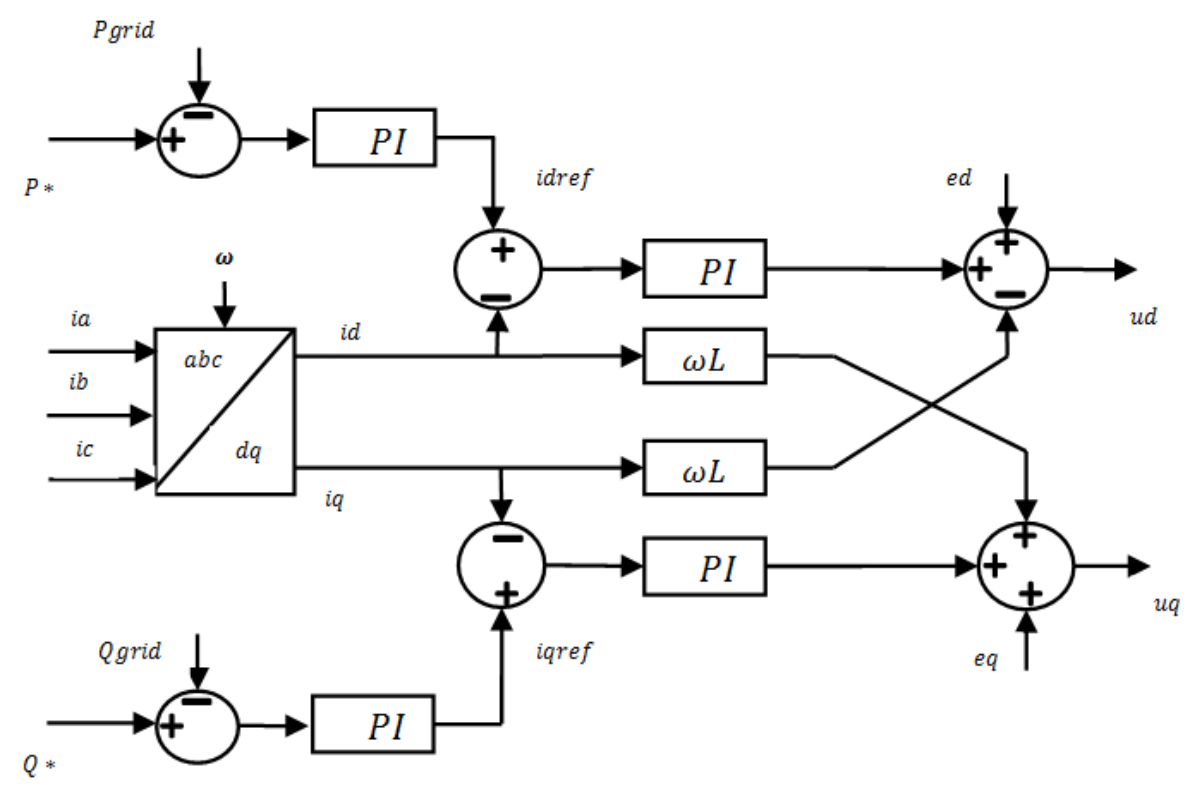

Fig. 2. Control structure showing the outer and inner loops

The synchronous reference frame transformation (abc/dq) is employed to calculate the dq components of converter currents. The phase locked loop is employed to generate individual sinusoidal signals which are synchronized in frequency and phase with the mains voltage. Then, the inner loops regulate the currents. The two PI controllers in the current-regulator control the daxis and q-axis currents and evaluate the ud and uq output voltages needed to generate the PWM signals. These PWM signals are used to drive the inverter.

This grid mode controller can be set to provide three different functions i.e., load leveling, fixed reactive power exchange and unity power factor operation.

\section{Load Leveling}

Load leveling can be defined as the process where power is conserved in the battery during light load conditions so that it can be utilized during the periods of high demand. Equation 1 represents this functionality.

$$
\mathrm{P}_{\text {batt }}=\mathrm{P}_{\text {load }}-\mathrm{P}_{\text {grid }}
$$

\section{Where:}

$\mathrm{P}_{\text {batt }}=$ Battery power

$\mathrm{P}_{\text {load }}=$ Load power demand

$\mathrm{P}_{\text {grid }}=$ Power supplied by the grid 
When $\mathrm{P}_{\text {load }}>\mathrm{P}_{\text {grid, }}$, the battery supplies power to the load and when $\mathrm{P}_{\text {load }}<\mathrm{P}_{\text {grid }}$, the additional power is used to charge the battery. Hence irrespective of load variations, the consumer can consume a constant amount of real power from the grid. This allows for the postponement of increasing the generation capacity and grid upgrades.

\section{Fixed Reactive Power Exchange (RPE) Mode}

As explained earlier, DSTATCOM can function in the capacitive or the inductive mode thereby generating or absorbing the reactive power from the grid. So, the control system is designed to facilitate this exchange of reactive power between grid and the proposed system by setting the reference $\mathrm{Q}_{\text {grid }}$ to a suitable value.

\section{Unity Power Factor (UPF) Mode}

In this mode, the entire reactive power requirement of the load is provided by DSTATCOM-BESS system and the grid needs to supply only the active power to the load. Thus the control algorithm is designed to increase the power factor of currents on the supply side.

To make the UPF operation possible, the reactive power demand from the grid is set at $\mathrm{Q}_{\text {grid }}=0$ and the entire load reactive power requirement will be met by the DSTATCOM-BESS system.

\section{Fault Detection and Mode Transfer}

When a fault happens in the grid, a distortion is impressed in the grid voltage and this can happen in different forms like voltage sag, swell, over voltage, under voltage (Vetrivel et al., 2013). There are various methods to identify faults. Signal processing and spectral analysis can be used for fault analysis (Ahmed et al., 2010; Intesar Ahmed et al., 2010; Swetha and Radhakrishna, 2015). The control system must detect such situation and disconnect the load from the main grid by opening the circuit breaker and switch over to voltage controller for the standalone mode of operation. For this, the RMS voltage method is used in this work to detect the grid faults and other interruptions (Banu et al., 2014). The RMS value of the grid voltage is calculated and when the grid voltages violate the limits, the control system disconnects the load opening the circuit breaker and switches over to voltage controller to the provide the necessary load power and to maintain constant load voltage.

\section{Uninterrupted Power Supply (UPS) or Standalone Mode}

In this mode of operation, the voltage and frequency of the load are controlled by the DSTATCOM - BESS system by switching over to the voltage controller. The block diagram for the voltage control of the stand alone mode employing the dq frame is shown in Fig. 3, which has with two different signals $V_{d}$ and $V_{q}$ responsible for the voltage magnitude and phase shift respectively. In this work, the voltage reference $V_{\text {dref }}$ will be regulated at $1 \mathrm{pu}$ and $\mathrm{V}_{\text {qref }}$ is set to 0 .

\section{Overall Structure of the Multimode Controller}

The various components of the multimode controller namely load leveling, DSTATCOM control, Standalone controller and fault detection mechanism are explained along with the smart functionalities. The overall multimode controller structure is represented in Fig. 4. The grid is providing the current Ig to the load and the compensation current I is provided by Voltage Sourced Converter (VSC) in grid-connected mode. When a fault is detected, the mechanism opens the Circuit Breaker (CB) and switches over to voltage controller and thus the VSC provides the necessary voltage to load from the BESS. The overall control algorithm of the proposed controller is shown in Fig. 5.

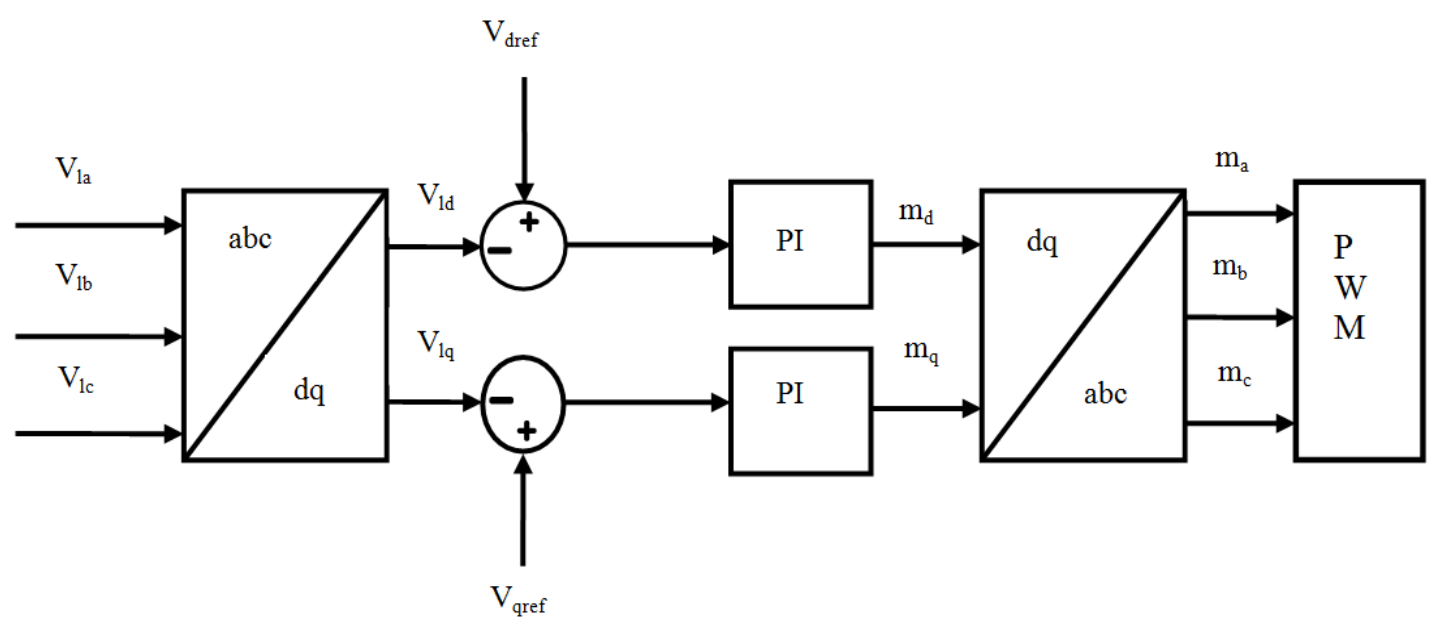

Fig. 3. Voltage Controller structure for standalone mode of operation 


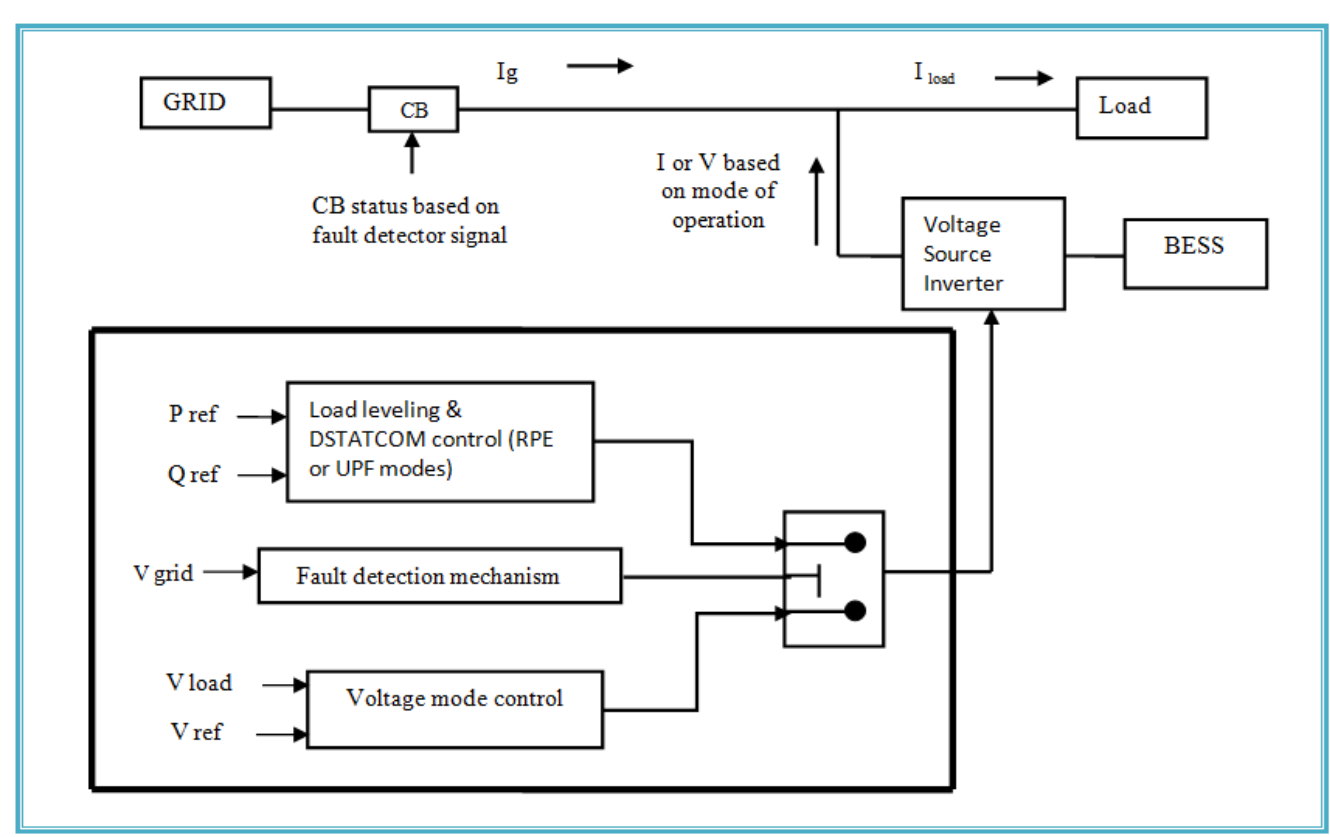

Fig. 4. The overall structure of multimode controller for DSTATCOM-BESS System

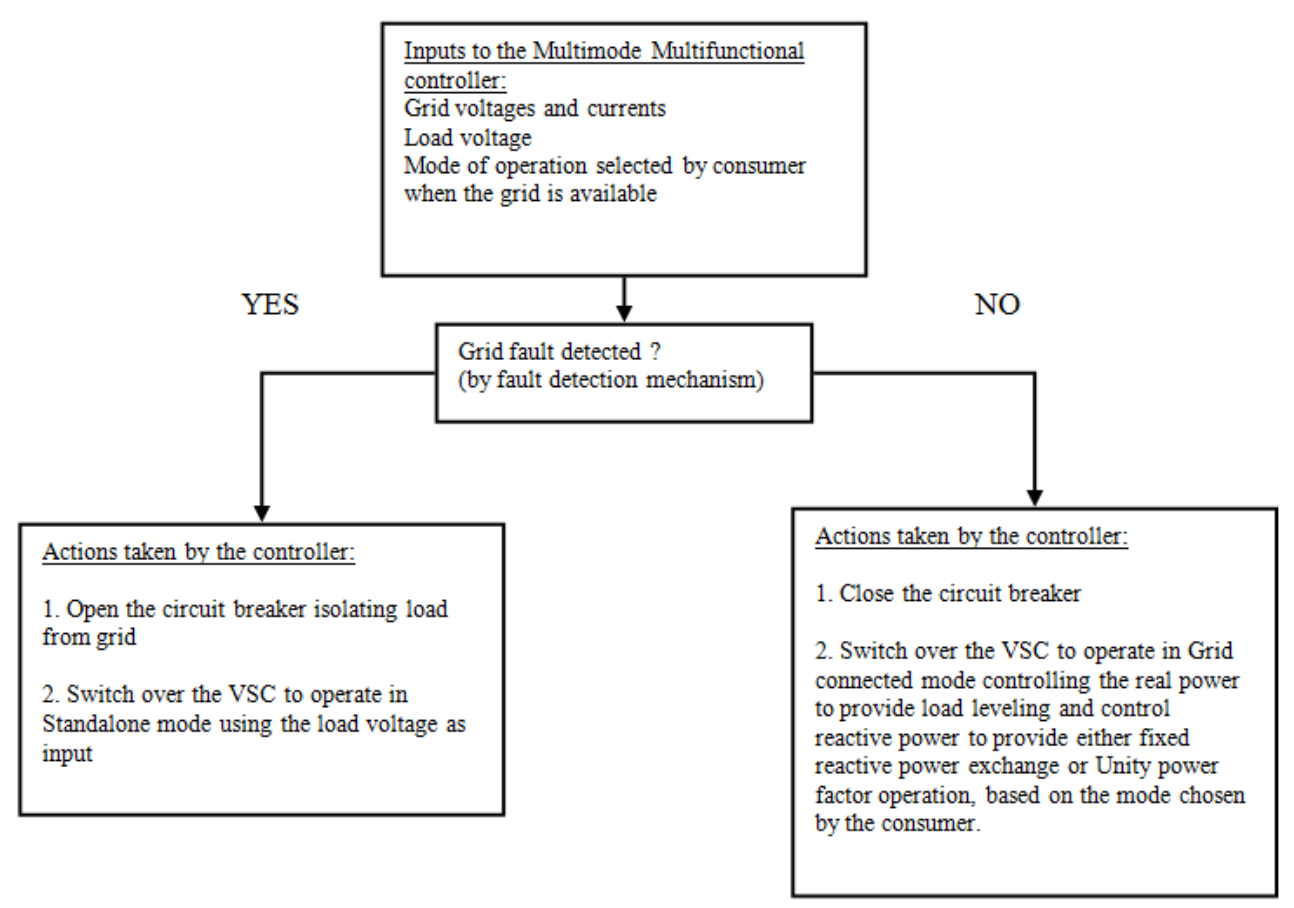

Fig. 5. The control algorithm for the multimode multifunctional controller

\section{Simulation and Discussion of Results}

The model for real and reactive power exchange between the grid and the DSTATCOM-BESS system is developed using SIMULINK. The voltage source converter is modeled as a 3-phase inverter using the Universal bridge block. The inverter is controlled using the multimode controller (Fig. 4) employing the control algorithm (Fig. 5) is utilized for both grid-connected mode and standalone modes. The battery model $(500 \mathrm{~V}$, $500 \mathrm{Ah}$ ) from SimPower Systems is used and a two dc link capacitors of $12 \mathrm{mF}$ each are employed. The inverter is connected to the grid system through a coupling transformer. Linear R-L loads are used for various case 
studies to demonstrate the functionalities and the reference powers and grid conditions may be changed as desired to test the performance of the proposed DSTATCOM-BESS system.

\section{Results for Various Test Cases}

\section{Performance of the DSTATCOM-BESS System with and without Load Leveling Functionality}

In the following study, the benefits of load leveling functionality is demonstrated by studying the performance of the DSTATCOM-BESS system with and without load leveling. The performance of the system without load leveling is shown in Fig. 6. The initial load real power demand was $80 \mathrm{~kW}$. At $0.5 \mathrm{~s}$, another load of $60 \mathrm{~kW}$ is added, thus increasing the load demand from $80 \mathrm{~kW}$ to $140 \mathrm{~kW}$. Again the second load is disconnected at $1.5 \mathrm{~s}$ and load demand is at $80 \mathrm{~kW}$ as shown in Fig. 6(a). It can be observed how real power supplied by the grid is changing with changing load demand in Fig. 6(b). Figure 7 shows the performance of the system with Load leveling function, where grid power is set constant at $100 \mathrm{~kW}$. In spite of changing load demand as shown in Fig. 7(a), it can be observed that the Pgrid is constant at $100 \mathrm{~kW}$ from Fig. 7(b). The variations in load demand are met by BESS as shown in Fig. 7(c). The load leveling functionality is performed by the battery, by absorbing the excess $20 \mathrm{~kW}$ during light loading and providing the additional $40 \mathrm{~kW}$ when load increases from $80 \mathrm{~kW}$ to $140 \mathrm{~kW}$. Thus grid power remains constant in spite of load variations because the battery takes care of changing load demands.
Performance of the DSTATCOM-BESS System with Fixed Reactive Power Exchange along with Load Leveling Functionality

In this study, the ability of the DSTATCOM-BESS system to exchange fixed reactive power along with providing load leveling functionality is demonstrated as shown in Fig. 8. In this case, a load of (50kW, 20kVAR) is considered and the load voltage remains constant throughout the operation as shown in Fig. 8(a). The grid real power demand is set at $100 \mathrm{~kW}$ using load leveling functionality and Pgrid remains constant throughout the operation as shown in Fig. 8(b). Figure 8(c) shows the change of reactive power exchange with the grid. Up to $0.5 \mathrm{~s}$, the consumer was supplying $50 \mathrm{kVARs}$ to the grid $\left(\mathrm{Q}_{\text {grid }}=50 \mathrm{kVAR}\right)$ and at $0.5 \mathrm{~s}$, when the reference is changed to $\mathrm{Q}_{\text {grid }}=-50 \mathrm{kVAR}$, the grid starts supplying $50 \mathrm{kVAR}$ to the consumer. This demonstrates the advantage of using indirect current control and using grid current values for power calculations, where the reactive power exchanged with the grid can be adjusted just by changing $Q_{\text {grid }}$ reference. Throughout the operation, the load requirement of Qload $=20 \mathrm{kVAR}$ is met as shown in Fig. 8(d). Figure 8(e) shows how DSTATCOM initially provided reactive power for the load $($ Qload $=20 \mathrm{kVAR})$ and the $\mathrm{Q}_{\text {grid }}\left(\mathrm{Q}_{\text {grid }}=50\right.$ $\mathrm{kVAR})$. After $0.5 \mathrm{~s}$, when the grid is providing the reactive power, the system switches to an inductive mode of operation and absorbs the reactive power. Out of the $50 \mathrm{kVAR}$ supplied by the grid, $20 \mathrm{kVAR}$ is consumed by load and some kVARs are lost in losses. The remaining reactive power is absorbed by the DSTATCOM. It has been observed that the proposed DSTATCOM-BESS system can exchange reactive power with the grid along with providing load leveling
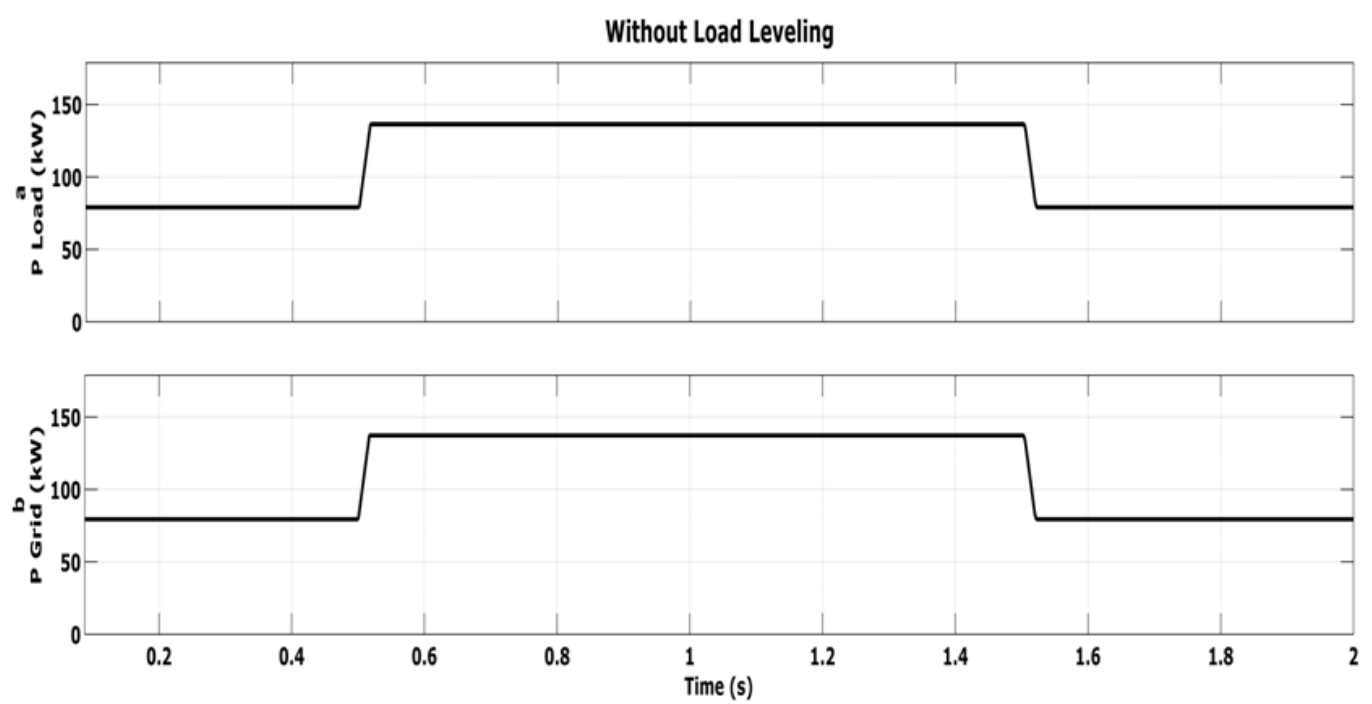

Fig. 6. Performance of the system without load leveling (a) load real power demand (kW) (b) real power supplied by grid (kW) 

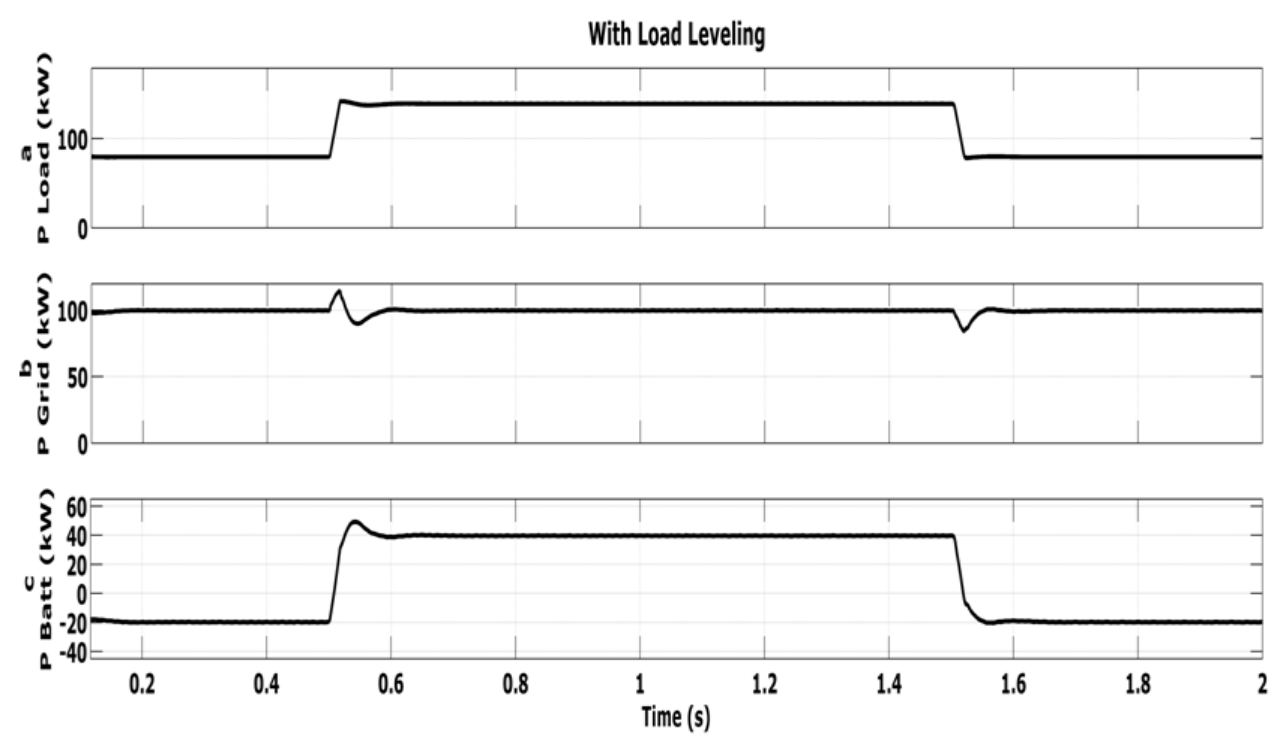

Fig. 7. Performance of the system with load leveling (a) load real power demand (kW) (b) real power supplied by the grid (kW) (c) real power supplied by the battery $(\mathrm{kW})$
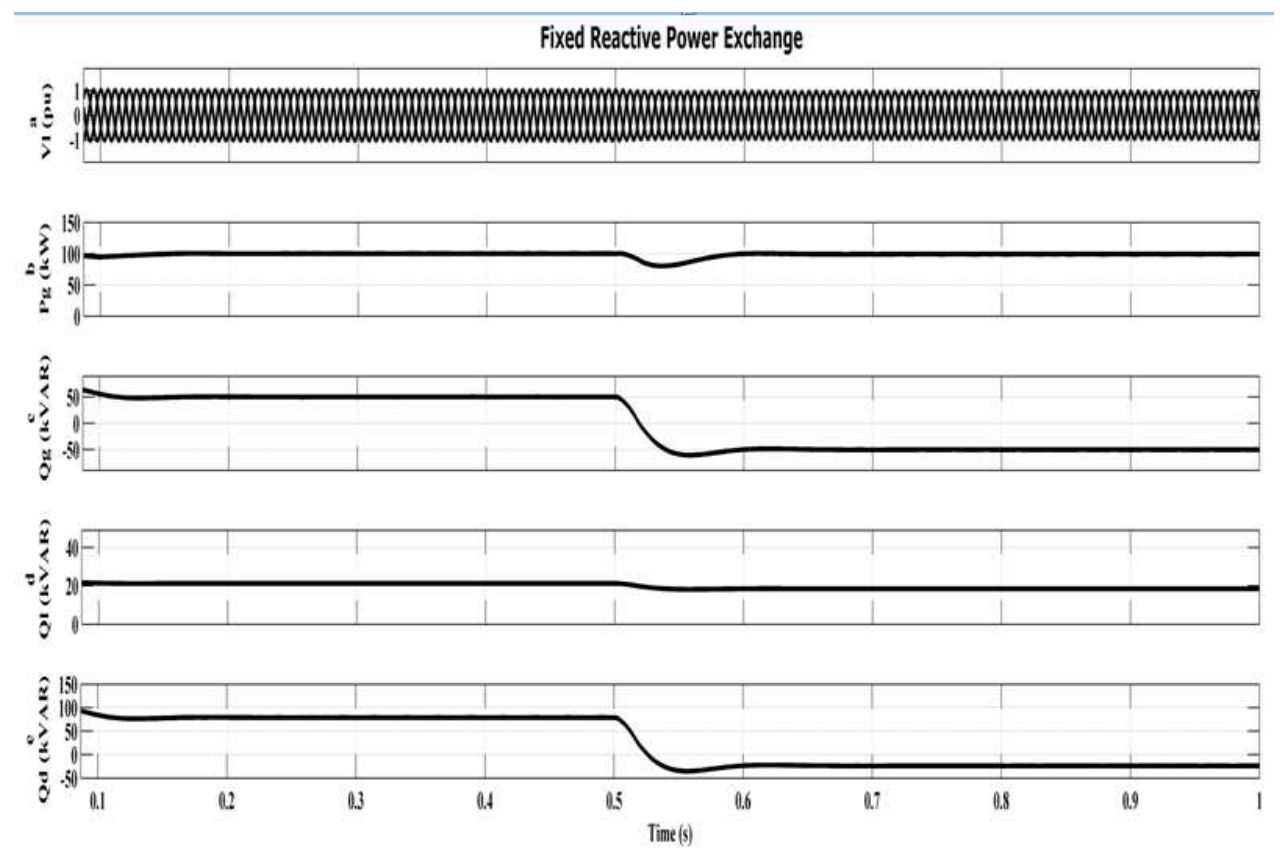

Fig. 8. Performance of the controller in reactive power exchange mode of operation with change in $\mathrm{Q}_{\text {grid }}$ reference at $0.5 \mathrm{~s}$ (a) load voltage (pu) (b) grid real power $(\mathrm{kW})(\mathrm{c})$ grid reactive power (kVAR) (d) load reactive power (kVAR) (e) DSTATCOM reactive power( $\mathrm{kVAR}$ )

Performance of the DSTATCOM-BESS System with Unity Power Factor Operation and Load Leveling Functionality

In this study, the ability of the DSTATCOM-BESS system to provide unity power factor operation with providing load leveling functionality is demonstrated as shown in Fig. 9. At UPF, the reactive power supplied by the grid is zero $\left(\mathrm{Q}_{\text {grid }}=0 \mathrm{kVAR}\right)$ and the DSTATCOM-BESS system will provide for the load reactive power and also compensate for the losses across the system. ( $\mathrm{Q}$ dstatcom $=$ $\mathrm{Q}$ load $+\mathrm{Q}$ losses). In this case, a load of $(50 \mathrm{~kW}$, $20 \mathrm{kVAR})$ is considered and at $0.5 \mathrm{~s}$, another load of $(50 \mathrm{~kW}$, $20 \mathrm{kVAR}$ ) is added to test the performance of the system. 
Unity Power Factor Mode
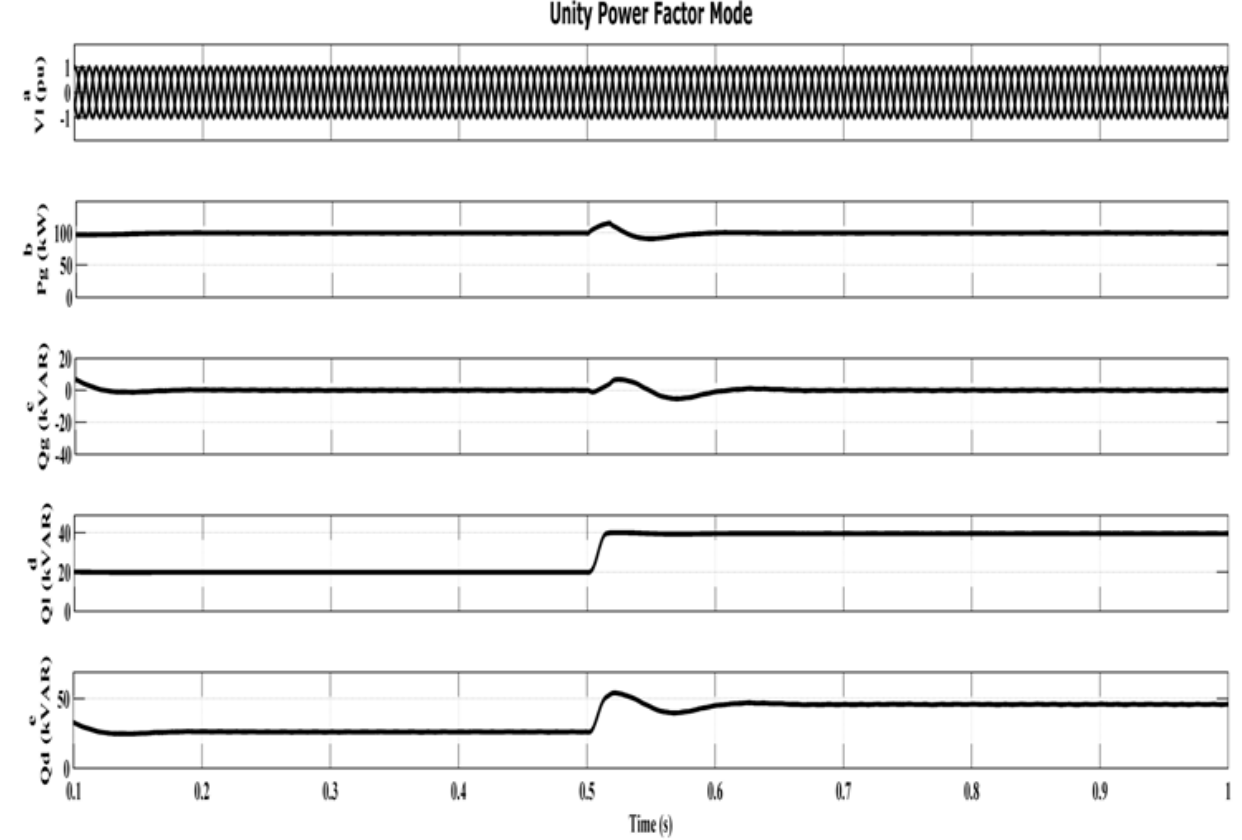

Fig. 9. Performance of the controller in unity power factor mode of operation (a) load voltage (pu) (b) grid real power $(\mathrm{kW})(\mathrm{c})$ grid reactive power (kVAR) (d) load reactive power (kVAR) (e) DSTATCOM reactive power (kVAR)

Fault detection and Mode Transition
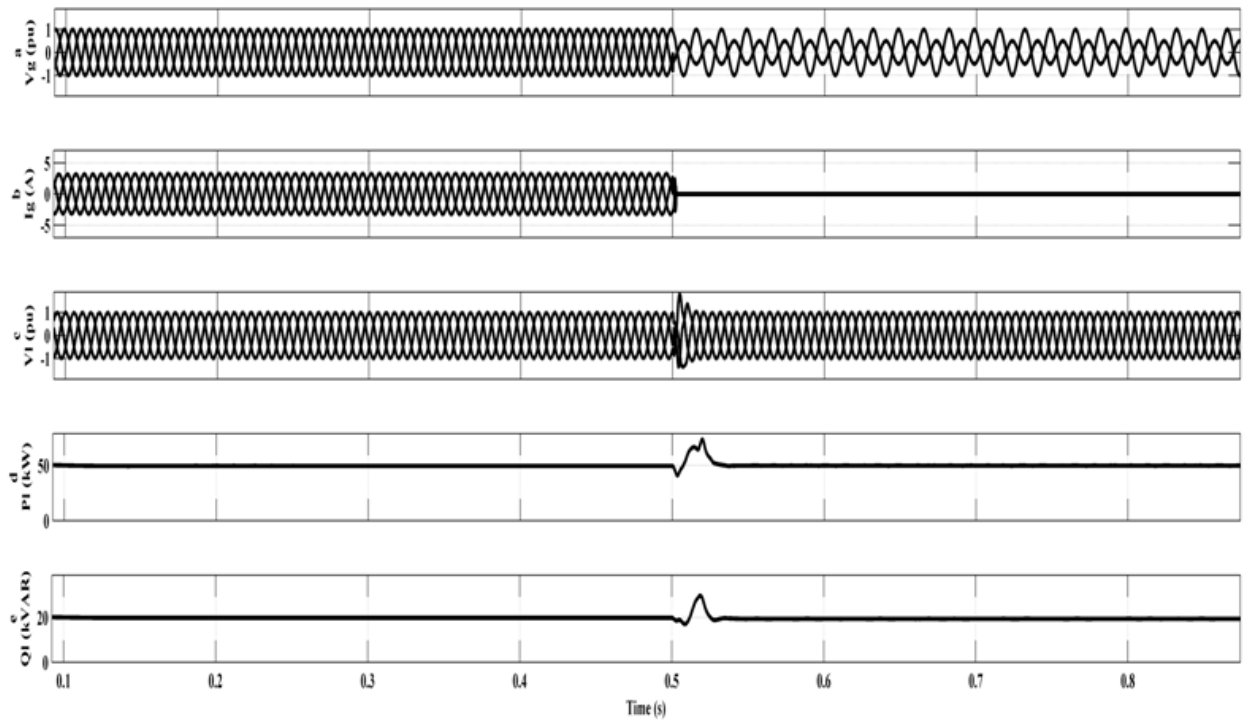

Fig. 10. Performance of the fault detection and isolation control during grid fault at $0.5 \mathrm{~s}$ (a) grid voltage (pu) (b) grid current (A) (c) load voltage $(\mathrm{pu})(\mathrm{d})$ load real power $(\mathrm{kW})(\mathrm{e})$ load reactive power $(\mathrm{kVAR})$

The load voltage remains constant throughout the operation as shown in Fig. 9(a). The grid real power demand is set at $100 \mathrm{~kW}$ using load leveling functionality and $\mathrm{P}_{\text {grid }}$ remains constant throughout the operation as shown in Fig. 9(b). Figure 9(c) shows that throughout the operation, the grid has not supplied reactive power $\left(\mathrm{Q}_{\text {grid }}=0\right.$ throughout the operation $)$. This shows the complete load reactive power requirements is provided by DSTATCOM. Figure 9(d) shows the initial load reactive power requirement of Qload $=20 \mathrm{kVAR}$ and after $0.5 \mathrm{~s}$ increased to $40 \mathrm{kVAR}$ by addition of load. DSTATCOM initially provided reactive power for the load (Qload $=20 \mathrm{kVAR})$ and the reactive losses across the system, further it is able to provide Qload of 40 
kVAR after $0.5 \mathrm{~s}$ enabling the Unity Power Factor operation. The remaining reactive power is absorbed by the DSTATCOM. It has been observed that the proposed DSTATCOM-BESS system can enable unity power factor operation along with providing load leveling.

\section{Fault Detection and Standalone Mode Operation of DSTATCOM-BESS System}

In this study, the ability of the proposed controller to detect the grid faults and switch the DSTATCOM-BESS system to the standalone mode of operation is demonstrated as shown in Fig. 10. A line to line fault is applied on the grid at $0.4 \mathrm{~s}$ and the grid voltage which was initially at $1 \mathrm{pu}$ is affected as shown in Fig. 10(a). The controller detects the fault and opens the circuit breaker at $0.5 \mathrm{~s}$, thus grid current supplied is zero after $0.5 \mathrm{~s}$ as shown in Fig. 10(b). The multimode controller switches over to the voltage controller to control the inverter after fault detection and the system has been switched to a standalone mode of operation. The voltage controller maintains the load voltage magnitude constant at $1 \mathrm{pu}$ after getting disconnected from the grid at $0.5 \mathrm{~s}$ as shown in Fig. 10(c). Figure 10(d) shows the load real power of $50 \mathrm{~kW}$ provided by the grid. After $0.5 \mathrm{~s}$, the battery supplies the needed real power. Figure 10(e) shows the load reactive power of $20 \mathrm{kVARs}$ provided by DSTATCOM. After $0.5 \mathrm{~s}$, the battery supplies the needed reactive power. It is observed that the controller has successfully detected the fault and has isolated the load from faulted grid opening the circuit breaker. Further, the voltage controller has maintained needed load voltage and supplied the needed load power with the help of battery in the standalone mode.

\section{Conclusion}

This paper has proposed the design and control of a multimode controller along with fault detection for a DSTATCOM integrated with the battery energy storage system to perform multiple functions like load leveling, fixed reactive power exchange, unity power factor improvement. From the results obtained, it can be concluded that the developed control algorithms work satisfactorily in all the modes of operation. The designed controller has satisfied the smart grid criteria by achieving satisfactory performance providing various functionalities to the consumer.

\section{Acknowledgement}

We acknowledge the reserach facilities provided by the Centre for Energy Studies, IIT Delhi to carry out this work.

\section{Author's Contributions}

Sai Pranith: Built the multimode controller and individual controllers. Drafted the content of the article.

T.S. Bhatti: Designed the reasearch plan. Organized the information across various sections.

\section{Ethics}

The corresponding author confirms that this article contains unpublished material. There are no ethical issues involved and the authors have read and approved the manuscript.

\section{References}

Ahmed, I., M. Ahmed, K. Imran, M. Shuja Khan and T. Akram et al., 2010. Spectral analysis of misalignment in machines using sideband components of broken rotor bar, shorted turns and eccentricity. Int. J. Electrical Computer Sci., 10: 77-85.

Akagi, H., E.H. Watanabe and M. Aredes, 2007. Instantaneous Power Theory and Applications to Power Conditioning. Hoboken, Wiley-IEEE Press, ISBN: 978-0-470-10761-4.

Alanne, K. and A. Saari, 2006. Distributed energy generation and sustainable development. Renewable Sustainable Energy Rev., 10: 539-558. DOI:10.1016/j.rser.2004.11.004

Banu, I.V., M. Istrate, D. Machidon and R. Pantelimon, 2014. A study on anti-islanding detection algorithms for grid-tied photovoltaic systems. Proceedings of the International Conference on Optimization of Electrical and Electronic Equipment, May, 22-24, IEEE Xplore press, Bran, Romania, pp: 655-660. DOI:10.1109/OPTIM.2014.6850940

Barghi Latran, M., A. Teke and Y. Yoldaş, 2015. Mitigation of power quality problems using distribution static synchronous compensator: A comprehensive review. IET Power Electronics, 8: 1312-1328. DOI: 10.1049/iet-pel.2014.0531

Bollen, M., J. Zhong, F. Zavoda, J. Meyer and A. McEachern et al., 2010. Power quality aspects of smart grids. Proceedings of the International Conference on Renewable Energies and Power Quality (ICREPQ'10), pp: 1061-1066.

Chen, B.S. and Y.Y. Hsu, 2008. A minimal harmonic controller for a STATCOM. IEEE Trans. Industrial Electronics, 55: 655-664. DOI: 10.1109/TIE.2007.896266

Gao, D.W., 2015. Chapter 5 - Sizing of energy storage systems for microgrids. Energy Storage Sustainable Microgrid.

DOI: 10.1016/B978-0-12-803374-6.00005-6 
Hamilton, B.A., J. Miller and B. Renz, 2010. Understanding the benefits of the smart grid. Strategy, NETL report, US Department of Energy.

Intesar Ahmed., Manzar Ahmed, M. Shuja Khan, Kashif Imran. 2010. Investigation of multiple faults detection in electric machine using broken rotor bar and eccentricity fault frequencies techniques. Int. J. Electrical Comput. Sci. 10: 22-30.

Isa, N.B.M., T.C. Wei and A.H.M. Yatim, 2015. Smart grid technology: Communications, power electronics and control system. Proceedings of the International Conference on Sustainable Energy Engineering and Application: Sustainable Energy for Greater Development, Oct. 5-7, IEEE Xplore press, Bandung, Indonesia, pp: 10-14. DOI: 10.1109/ICSEEA.2015.7380737

Mahela, O. P. and A.G. Shaik, 2016. Power quality improvement in distribution network using DSTATCOM with the battery energy storage system. Int. J. Electrical Power Energy Systems, 83: 229-240. DOI: 10.1016/j.ijepes.2016.04.011.

Molina, M. and P.E. Mercado, 2006. Control design and simulation of DSTATCOM with energy storage for power quality improvements. Transmission and Distribution Conference and Exposition: Latin America, Aug. 15-18, IEEE Xplore press, pp: 1-7. DOI: 10.1109/TDCLA.2006.311436

Pal, Y., Swarup, A., and B. Singh., 2008. A review of compensating type custom power devices for power quality improvement. Proceedings of the IEEE Power India Joint International Conference on Power System Technology, Oct. 12-15, IEEE Xplore press, New Delhi, India.

DOI: $10.1109 /$ ICPST.2008.4745338
Reddy, J.G.P. and K.R. Reddy, 2012. Design and simulation of cascaded H-bridge multilevel inverter based DSTATCOM for compensation of reactive power and harmonics. Proceedings of the 1st International Conference on Recent Advances in Information Technology, March, 15-17, pp: 737-743. DOI: 10.1109/RAIT.2012.6194546

Shuja Khan, M., I. Intesar, M.S. Raheel, M. Babar Ali and U. Asad et al., 2011. Implementation of a passive tune filter to reduce harmonics in single phase induction motor with varying load, Int. J. Engineering Technology, 11: 204-208.

Singh, B., A. Chandra and K. Al-Haddad, 2015. Power Quality Problems and Mitigation Techniques, Wiley Publishers, ISBN-10: 978-1-118-92205-7

Swetha, A. and A. Radhakrishna, 2015. Signal processing techniques for power system fault analysis-A review. Int. J. Innovative Res. Scie. Eng. Technology. DOI: 10.15680/IJIRSET.2015.0408089

The ABB Group, Energy Storage Brochure, 2012. Energy storage keeping smart grids in balance.

Vetrivel, A., J. Jerome and N. Malmurugan, 2013. A novel method of voltage sag and swell estimation for power system applications. Am. J. Eng. Applied Sci., 6: 233-240.

DOI: 10.3844/ajeassp.2013.233.240

Virulkar, V. and M. Aware, 2009. Analysis of DSTATCOM with BESS for mitigation of flicker. Proceedings of the International Conference on Control, Automation, Communication and Energy Conservation, June 4-6, IEEE Xplore press, Tamilnadu, India.

Zurfi, A., and J. Zhang. 2016. Exploitation of battery energy storage in load frequency control -a literature survey. Am. J. Engineering Applied Sci., 9: 1173.1188. DOI: 10.3844/ajeassp.2016.1173.1188 